\title{
Modeling the decision-making problem for multi-connected technical systems based on expert knowledge
}

\author{
Mukhtar Kerimov ${ }^{1, *}$, Irina Belinskaia ${ }^{2}$, and Oleg Ognev ${ }^{1}$ \\ ${ }^{1}$ Saint Petersburg State Agrarian University, 196601, Peterburgskoe shosse, 2, Pushkin, Saint \\ Petersburg, Russia, \\ ${ }^{2}$ The Leningrad State University after named A.S. Pushkin, 196605, Peterburgskoe shosse, 10, \\ Pushkin, Saint-Petersburg, Russia
}

\begin{abstract}
The problem of evaluating the effectiveness of a carousel-type grain dryer is considered. To solve this problem, we used the fuzzyprobability approach of Zadeh-Mamdani, based on expert knowledge. The substantiation of the factor space systemically describing the functioning of the grain dryer is carried out. A fuzzy probability model is constructed in the space of linguistic variables. The article presents a method for constructing a functioning model of the carousel-type grain dryer, which allows obtaining quantitative estimates of the technological process state in a four-dimensional space of linguistic variables. It is established that to ensure the technological reliability of the grain drying process in carouseltype installations, it is necessary to use an automatic control system based on operational control of the system output parameters.
\end{abstract}

\section{Introduction}

The need to remove excess moisture that affects the safety of quality indicators of freshly harvested grain mass determines drying as the main and mandatory production operation in post-harvest grain processing technologies. This operation is particularly important for those agro-industrial enterprises located in the North-Western region of Russia, where the probability of conditioned humidity of harvested grain does not exceed 0.1 [1].

During post-harvest grain processing, drying is also the most energy-consuming technological operation. Its share is $70 \ldots 75 \%$ from all costs associated with bringing the processed grain mass to the required indicators for humidity and clogging. When drying grain, the irrational consumption of heat energy is 58.3 MJ per $1 \%$ of excessively evaporated moisture per ton of grain. Therefore, optimization of the technological process of drying high-moisture grain heaps as an engineering task is of scientific value and practical significance.

The purpose of the research is to develop a methodology for evaluating the effectiveness of the grain drying unit on the basis of a set-theoretic approach to the use of expert knowledge and their formalization for implementation in computer technologies.

\footnotetext{
* Corresponding author: martan-rs@yandex.ru
} 


\section{Material and methods}

The set-theoretic formulation and solution of the problem of the grain dryer functioning quality is based on the use of expert knowledge [2,3].

The processing of meta-knowledge that the expert has includes three consecutive stages (Fig. 1):

$1 . g_{1}: M Z^{E}(q, t, \mu) \rightarrow Z_{K}^{E}(q, t, \mu)$ - the extraction of the expert metaknowledge $M Z^{E}(q, t, \mu)$ - sets of variables that describe the state of a specific technical object $Z_{K}^{E}(q, t, \mu)$ Factors are considered as variables, the most important of which are taken into account in decision-making [4].

2. $g_{2}: Z_{K}^{E}(q, t, \mu) \rightarrow Z_{F P}^{E}(q, t, \mu)$ - the process of representing expert knowledge (parameterization) in the form of linguistic variables and the formation of a factor $\operatorname{space} Z_{F P}^{\ni}(q, t, \mu)$

3. $g_{3}: Z_{F P}^{E}(q, t, \mu) \rightarrow Y / \sum$ - the process of formalizing explicit and implicit expertise is one of the possible ways to build a model.

Here $Y / \Sigma$ - a pre-developed scale of classes, one of which should include the specific state of the object calculated from the model.

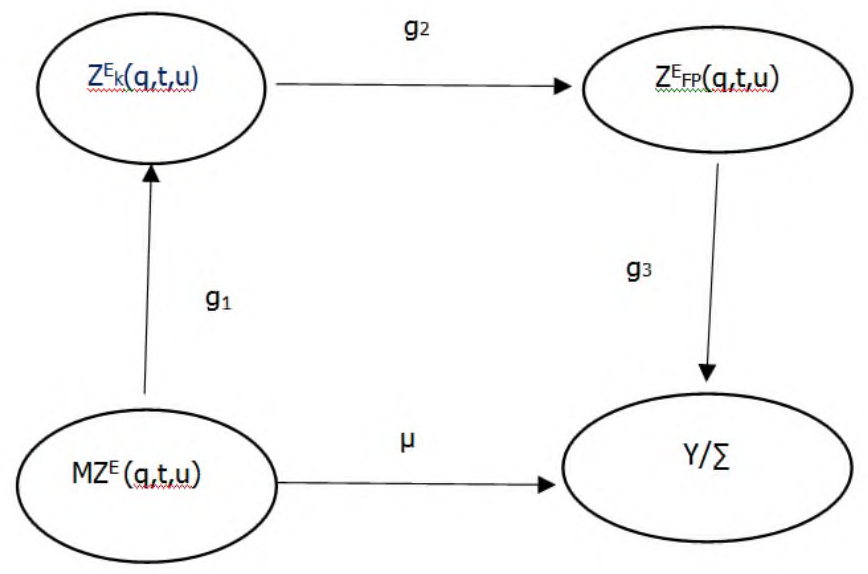

Fig. 1. Communicative scheme for processing explicit and implicit expert meta-knowledge

The set of relations that express the connections between the considered sets is a formalization of expert knowledge in the form of a logical-linguistic model [5].

To substantiate the factor space as a working environment for modeling, the parameters that most fully characterize the technological process of grain drying are used.

The following variables are selected as managed parameters:

$\mathrm{x}_{1}$ - humidity of the grain crop, $\%$;

$\mathrm{x}_{2}-$ deviation of the drying agent temperature from the values set by agrotechnical requirements, $\%$; $\%$;

$\mathrm{x}_{3}$ - deviation of the grain layer height in the drying chamber from the optimal value,

$\mathrm{x}_{4}$ - exposure of the grain layer in the drying chamber, sec.

The dependent variable $\mathrm{Y}$ as a generalized indicator of the function $\mathrm{Y}(\mathrm{t})$ characterizes the efficiency of the grain dryer [6]. 
In the linguistic form, the components of the factor space are shown in figure 2 (for example, the indicator $\mathrm{x}_{1}, \mathrm{x}_{1}-\mathrm{g}$-gain moisture):

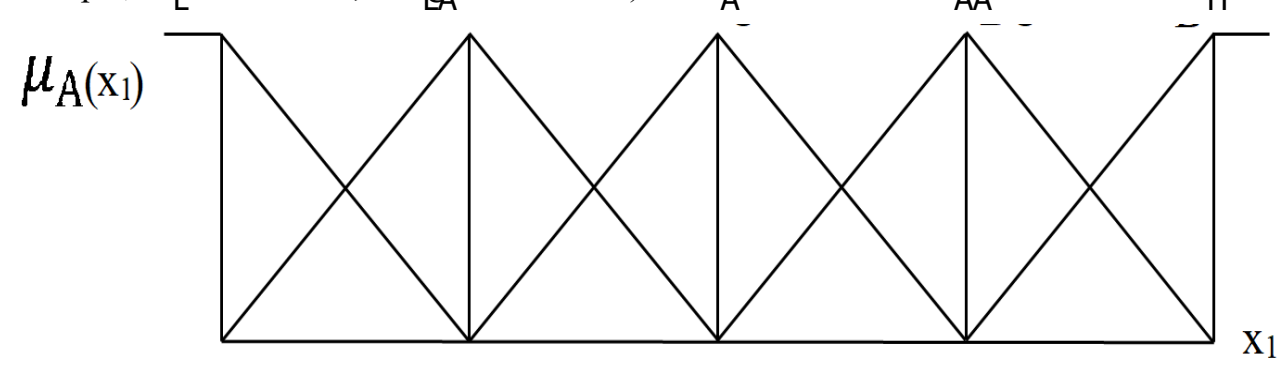

Fig. 2. Representatipn of the factor space component $x_{1}$ as 28 dinguistic variable 21 14 L-low level; LA-lower than average level; A-average level; AA-above average level; $\mathrm{H}$ - high level

The verbal characteristics for converting them to numerical form (arithmetic) are shown in table 1 .

Table 1. Verbal characteristics of the output value Y (grain drying quality)

\begin{tabular}{|c|c|c|}
\hline $\begin{array}{c}\text { Interval } \\
\text { boundaries }\end{array}$ & $\begin{array}{l}\text { Interval mode and } \\
\text { its notation }\end{array}$ & Characteristic of the output value interval $Y$ \\
\hline 0,7 and higher & 0,7 (high) & $\begin{array}{l}\text { The value of the probability of being } \mathrm{Y} \text { in the } \\
\text { tolerance field } P_{\Delta} \geq 0,8 \text {. } \\
\text { Compliance with agricultural requirements (in } \\
\text { terms of productivity) is more than } 80 \% \text { of the } \\
\text { dried grain mass.. }\end{array}$ \\
\hline $0,5-0,7$ & $\begin{array}{c}0,6 \text { (above the } \\
\text { average) }\end{array}$ & $\begin{array}{l}\text { The value of the probability of being } \mathrm{Y} \text { in the } \\
\text { tolerance field } P_{\Delta} \geq 0,7 \text {. } \\
\text { The spread of humidity in the grain layer is at a } \\
\text { level below average (according to the } \\
\text { performance of the grain dryer). }\end{array}$ \\
\hline $0,4-0,6$ & 0,5 (average) & $\begin{array}{l}\text { The value of the probability of being } \mathrm{Y} \text { in the } \\
\text { tolerance field } P_{\Delta} \geq 0,6 \\
\text { The spread of humidity in the grain layer is at } \\
\text { an average level (according to the performance } \\
\text { of the grain dryer). }\end{array}$ \\
\hline $0,3-0,5$ & 0,4 (lower average) & $\begin{array}{l}\text { The value of the probability of being } \mathrm{Y} \text { in the } \\
\text { tolerance field } P_{\Delta} \geq 0,5 . \\
\text { The spread of humidity in the grain layer is at } \\
\text { an average level (according to the performance } \\
\text { of the grain dryer). }\end{array}$ \\
\hline 0,3 and lower & 0,3 (low) & $\begin{array}{l}\text { The value of the probability of being } \mathrm{Y} \text { in the } \\
\text { tolerance field } P_{\Delta} \geq 0,4 \\
\text { The level of humidity dispersion in the grain } \\
\text { layer is high. }\end{array}$ \\
\hline
\end{tabular}




\section{Results and discussion}

Expert estimates are taken into account in the survey matrix in the form of extreme values of input linguistic variables (table 1). Each row is interpreted as the result of converting the components of the combination "situation - state of the object" in accordance with the rule "if ..., then ..." [7].

Table 2. Matrix of expert survey and calculated performance indicators 23320 , of the carousel type grain dryer

\begin{tabular}{|c|c|c|c|c|c|c|c|c|c|}
\hline \multirow{3}{*}{ № } & \multirow{3}{*}{ 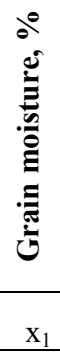 } & \multirow{3}{*}{ 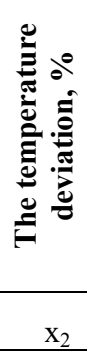 } & \multirow{3}{*}{ 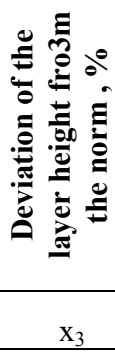 } & \multirow{3}{*}{ 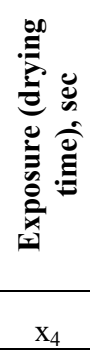 } & \multicolumn{5}{|c|}{ The quality of drying, $Y$} \\
\hline & & & & & \multicolumn{2}{|c|}{$\begin{array}{c}\text { Expert } \\
\text { evaluation }\end{array}$} & \multicolumn{3}{|c|}{ Calculation by model } \\
\hline & & & & & $\mathrm{Y}_{\mathrm{e}}$ & $\mathrm{Y}_{\mathrm{e} 1}$ & $\mathrm{Y}_{1}$ & $\mathrm{Y}_{\mathrm{e} 2}$ & $\mathrm{Y}_{2}$ \\
\hline 1 & -1 & -1 & -1 & -1 & $\mathrm{~L}$ & 40 & 39,688 & 0,3 & 0,297 \\
\hline 2 & 1 & -1 & -1 & -1 & LA & 50 & 50,313 & 0,4 & 0,403 \\
\hline 3 & 1 & 1 & -1 & -1 & $\begin{array}{l}\text { L- } \\
\text { LA } \\
\end{array}$ & 45 & 45,938 & $\begin{array}{c}0,3 \\
5 \\
\end{array}$ & 0,359 \\
\hline 4 & 1 & 1 & -1 & -1 & A & 60 & 59,063 & 0,5 & 0,491 \\
\hline 5 & -1 & -1 & 1 & -1 & LA & 50 & 51,563 & 0,4 & 0,416 \\
\hline 6 & 1 & -1 & 1 & -1 & $\begin{array}{c}\text { LA- } \\
\text { A }\end{array}$ & 55 & 54,688 & $\begin{array}{c}0,4 \\
5 \\
\end{array}$ & 0,447 \\
\hline 7 & -1 & 1 & 1 & -1 & LA & 50 & 47,813 & 0,4 & 0,378 \\
\hline 8 & 1 & 1 & 1 & -1 & $\mathrm{~A}$ & 60 & 60,938 & 0,5 & 0,509 \\
\hline 9 & -1 & -1 & -1 & 1 & A & 60 & 59,688 & 0,5 & 0,497 \\
\hline 10 & 1 & -1 & -1 & 1 & $\begin{array}{l}\mathrm{A}- \\
\mathrm{AA}\end{array}$ & 65 & 64,063 & $\begin{array}{c}0,5 \\
5 \\
\end{array}$ & 0,541 \\
\hline 11 & -1 & 1 & -1 & 1 & A & 60 & 59,688 & 0,5 & 0,497 \\
\hline 12 & 1 & 1 & -1 & 1 & $\begin{array}{l}\mathrm{A}- \\
\mathrm{AA} \\
\end{array}$ & 65 & 66,563 & $\begin{array}{c}0,5 \\
5 \\
\end{array}$ & 0,566 \\
\hline 13 & -1 & -1 & 1 & 1 & $\mathrm{AA}$ & 70 & 69,063 & 0,6 & 0,591 \\
\hline 14 & 1 & -1 & 1 & 1 & $\begin{array}{l}\mathrm{A}- \\
\mathrm{AA} \\
\end{array}$ & 65 & 65,938 & $\begin{array}{c}0,5 \\
5 \\
\end{array}$ & 0,559 \\
\hline 15 & -1 & 1 & 1 & 1 & $\mathrm{AA}$ & 70 & 71,563 & 0,6 & 0,616 \\
\hline 16 & 1 & 1 & 1 & 1 & $\mathrm{H}$ & 80 & 78,438 & 0,7 & 0,684 \\
\hline
\end{tabular}

Calculations of the dependent variable $\mathrm{Y}$ are performed in two ways. A model for the variation of the drying quality $\mathrm{Y}_{1}$ as a percentage is constructed on the $\mathrm{Y}_{\mathrm{E} 1}$ scale. For the second variant, changes in the dependent variable $\mathrm{Y}_{2}$ are presented in a scale of subjective probability from 0.3 to $0.7[8,9]$. 
The model obtained using the methods of experiment planning theory has the following form:

$$
\begin{gathered}
Y_{1}=59,063+3,438 x_{1}+2,188 x_{2}+3,438 x_{3}+7,813 x_{4}+1,563 x_{1} x_{2}-0,938 x_{1} x_{3}-1,563 x_{1} x_{4}+ \\
0,938 x_{3} x_{4}+0,938 x_{1} x_{2} x_{3}+1,563 x_{2} x_{3} x_{4}
\end{gathered}
$$

To evaluate the accuracy of calculations based on the specified model, will use the criterion [10-11]

$$
S_{\text {res }}=\sqrt{\frac{\left(Y_{K E}-Y_{K C}\right)^{2}}{m-l}}
$$

where $S_{\text {res }}$ - residual mean square deviation

$Y_{K E}, Y_{K C}$ - accordingly, the expert assessment and the calculated value for the $\mathrm{K}$-th row of the matrix;

$\mathrm{m}-$ the number of rows in the matrix.

1 - the number of imposed links.

The correctness of calculations is ensured by observing the following conditions

$S_{\text {res }}=1,67<S_{\mathrm{E}}=5$;

where $S_{\text {res }}$ - fuzzy expert information equal to half the distance between modes $\mathrm{Y}$ $[12,13]$.

The adequacy of the polynomial model is confirmed by a series of experimental studies conducted in the North-West region of Russia on grain material with an initial humidity of $\mathrm{W}=24 \ldots 29 \%$ during the harvesting seasons in $1991 \ldots 2019$ [1].

In order to extract additional information from the developed model, will use the apparatus of partial derivatives for all variables (3) and calculate the gradient of the function $\mathrm{Y}(4)$.

$$
\left.\begin{array}{c}
\frac{\partial Y}{d x_{1}}=3,438+1,563 x_{2}-0,938 x_{3}-1,563 x_{4}+0,938 x_{2} x_{3} ; \\
\frac{\partial Y}{d x_{2}}=2,188+1,563 x_{1}+0,938 x_{1} x_{3}+1,563 x_{3} x_{4} ; \\
\frac{\partial Y}{d x_{3}}=3,438-1,563 x_{1}+0,938 x_{1} x_{2}+1,563 x_{2} x_{4} ; \\
\frac{\partial Y}{d x_{4}}=7,813-1,563 x_{1}+0,938 x_{3}+1,563 x_{2} x_{3} .
\end{array}\right\}
$$

The gradient of the function is determined by the formula [1]

$$
\operatorname{grad} Y=\sqrt{\sum_{m=1}^{4}\left(\frac{\partial Y}{\partial x_{1}}\right)^{2}}
$$

The values of partial derivatives and gradients calculated using the above method are summarized in table 3 .

The partial derivatives that characterize the change of the dependent variable $\mathrm{Y}$ along the corresponding variables, as can be seen from the obtained expressions (3), are nonlinear. This indicates weakly formalized relationships between variables and complex kinematic and physical processes that occur in the grain dryer during its operation.

The ambiguous nature of the change in the gradient of the function indicates the need for additional research in the subject area [14-16]. 
Table 3.Values of partial derivatives and gradient of the function in different states of the system

\begin{tabular}{|c|c|c|c|c|c|}
\hline $\mathrm{x}_{\mathbf{1}}-\mathrm{x}_{\mathbf{4}}$ & $\frac{\boldsymbol{\partial Y}}{\boldsymbol{d x _ { \mathbf { 1 } }}}$ & $\frac{\boldsymbol{\partial Y}}{\boldsymbol{d} \boldsymbol{x}_{\mathbf{2}}}$ & $\frac{\boldsymbol{\partial Y}}{\boldsymbol{d x _ { \mathbf { 3 } }}}$ & $\frac{\boldsymbol{\partial Y}}{\boldsymbol{d} \boldsymbol{x}_{\mathbf{4}}}$ & $\operatorname{grad} \boldsymbol{Y}$ \\
\hline-1 & 5,31 & 3,13 & 5,94 & 10,00 & 13,16 \\
\hline$-0,5$ & 4,14 & 2,03 & 4,06 & 8,52 & 10,50 \\
\hline 0 & 3,44 & 2,19 & 3,44 & 7,81 & 9,46 \\
\hline 0,5 & 3,20 & 3,59 & 4,06 & 7,89 & 10,10 \\
\hline 1 & 3,44 & 6,25 & 5,94 & 8,75 & 12,76 \\
\hline
\end{tabular}

\section{Conclusion}

1. Most technical objects and technological processes in agricultural production, including grain drying in carousel-type installations, must be considered as multi-connected systems. This problem statement is particularly relevant for systems that operate under conditions of of the source information significant uncertainty.

2. The construction of a model for evaluating the effectiveness of a carousel-type grain dryer is based on the fuzzy-probability approach of Zadeh-Mamdani.

Using a polynomial model, quantitative estimates of the state of the processing object in a 4-dimensional space of independent variables are calculated.

The method of constructing a mathematical model of the technological process of grain drying in the form of a polynomial dependence is developed. Using this model, quantitative estimates of the state of the processing object in a 4-dimensional space of independent variables are calculated.

3. Research has found that the violation of grain drying technology leads to a deterioration in the quality of finished products. Thus, changing the variable $\mathrm{x} 1$-humidity of the heap by $1 \%$ leads to a change in the generalized indicator of drying quality by $1 \%$.

The combined deviation of humidity and grain heating temperature from the standard values leads to a decrease in the quality of drying by $7 \ldots 10 \%$.

For the drying chamber, based on the model, a rational layer of dried grain with a thickness of $0.30 \ldots 0.35 \mathrm{~m}$ is calculated, which will allow to reduce energy costs by 2 times for drying one ton of product.

4. A comparative analysis of the efficiency of using grain dryers of various types. We compared the quality of functioning of the mine, drum and carousel grain dryers obtained in the course of research. As a result of calculations on the model, the following generalized indicators are obtained on a scale from 0.3 to 0.7 :

- carousel grain dryer- 0.56 ;

- mine grain dryer- 0.44

- drum dryer-0.41.

Based on the generalized criterion, the most efficient and least resource-consuming is a carousel-type grain dryer.

5. Proposed method for evaluating the performance of grain drying units is universal, and it can be used in multi-connected systems in order to optimize their technical and technological parameters.

The resulting fuzzy-probability model should be used as an element of the knowledge base when developing an automatic control system for the technological process of grain drying in carousel-type installations. 


\section{References}

1. M. Kerimov, Multi-criteria assessment of the various types grain dryers quality of functioning. Proceedings of the XXIII International scientific and practical conference 3, 310-315 (2019)

2. T.L. Saaty, L.G. Vargas, Models, methods, concepts \& applications of the analytic hierarchy process (2nd ed.), 345 (Boston: Kluwer Academic Publishers, 2012)

3. A. Imran, N. Athapol, Grain Process Engineering. Handbook of Farm, Dairy and Food Machinery Engineering 267-298 (2019)

4. M. Dehghani-Madisen, On the interval generalized coupled matrix equation, Electronic Journal of Linear Algebra, 34(1), 695-717 (2018)

5. A.M. Manshuk, E.D. Zhanagul, Z.M. Kairanbek, Automation and management of process grain drying. Theoretical \& Applied Science, 24(04) 177-184 (2015)

6. M. Dehghani-Madisen, M. Dehghan, Parametric AE-solutions set parametric matrix equation, Numeral Algorithms, 73(1) 245-279 (2016)

7. M. Ignatyev, V. Marley, Multi-Model Approach to City Governence in the Face of Uncertainty. Digital Transformation and Global Society, 469-477 (2016) http://dtgs.ifmo.ru/dtgs-2016.html (Last accessed 13.06.2020)

8. T. Haqiri, M.M. Moghadam, A. Rivaz, The united stable set of interval continuoustime algebraic Riccati equation and verified numerical computation of its outer estimation. Turkish Journal of Mathematics, 42(3) 1130-1155 (2018)

9. B. Everitt, Cluster analysis. Chichester, 330 (West Sussex, UK: Wiley, 2011)

10. Y. Robinson, Graph databases: new opportunities for working with related data, 256 (2016)

11. V. Zorich Mathematical analysis, Part I 564, Part II 676 (2015)

12. Z. Boberr, Family development as an area of marginal manifestations of environments. Perekonna areng kui ümbritsevate keskkondade marginaalsete nähtuste valdkond Actual problems of Economics and management, 4 (2017)

13. H. Knudsen, B.-T. Flåten, J. Falkenberg, J. Holbek, Å. Johnsen, I.G. Stensaker Strategisk ledesle (Oslo, Cappelen Damm akademisk, 2015)

14. A. Weidenfeld, P. Bjork, A.M. Williams, Knowledge transfer and relational proximity between service managers and customers in cross border regions. 17th Uddevalla Symposium 2014: Geography of Growth. The Frequency, Nature and Consequences of Enterpreneurship and Innovation in Regions of Varying Density, Uddevalla. (2014).

15. G. Zhang, Multi-Level Decision Making Models: Methods and Applications, ed. Guangquan Zhang, Jie Lu, Ya Gao, 377 (Berlin; Heidelberg : Springer-Verlag, 2015)

16. K. Grzybowska, The modelling and design process of coordination mechanisms in the supply chain. Journal of Applied Logic 24(A), 25-38 (2017) 